\title{
The Shortage of Organs for Clinical Transplantation: Document for Discussion
}

\author{
BRITISH TRANSPLANTATION SOCIETY
}

British Medical fournal, 1975, 1, 251-255

\section{Terms of Reference}

The terms of reference were to report to the British Transplantation Society on the following matters:

(a) How serious is the shortage of donor organs? (Section 1).

(b) What are the factors responsible for the shortage? (Section 2).

(c) To consider the law, the procedures adopted by coroners, criteria for establishing death, in particular brain death, and ethical matters concerning the care of the donor relating to the medical and nursing professions and the general public (Sections 3,4 , and 5 ).

(d) In the light of these discussions to recommend procedures for improving the supply of donor organs (Sections 6 and 7).

\section{How Serious is the Shortage of Donor Kidneys ?}

The four transplantation surgeons present were in agreement that there was a grave shortage of kidneys for transplantation; 450 kidneys a year were being transplanted in the United Kingdom, whereas around 2000 people a year needed transplants. It was difficult to establish an exact figure of those requiring transplantatinn, but it was felt that many patients

\footnotetext{
Editor: L. BRENT.

Members of Subcommittee: Mr. A. D. BARNES, Consultant Surgeon, B irmingham. Professor R. Y. CALNE, F.R.S., Professor of Surgery, University of Cambridge (chairman). Dr. O. Gillie, Medical Correspondent, Sunday Times. Mr. J. Hopewell, Consultant Surgeon, Royal Free Hospital. The Right Reverend Trevor HudDleston, C.R., Bishop of Stepney. Professor B. JeNNETT, Professor of Neurosurgery, University of Glasgow. Mr. R. A. SELLS, Consultant Surgeon, Liverpool. Mr. P. D. G. SKEGG, Fellow of New College, Oxford and Lecturer in Law, University of Oxford. Dr. G. THURSTON, H.M. Coroner, Inner West London. Mr. R. S. HuGHES, of the Department of Health and Social Security, attended as an observer.
}

were dying of kidney disease without the offer of dialysis or transplantation. As some transplants failed in patients who could subsequently receive second grafts, more kidneys were needed than appeared in most estimates. Several transplantation centres had virtually ceased work, and no centre was working to full capacity. The shortage of donor kidneys blocked access to treatment of new patients with chronic renal failure.

In the United Kingdom most kidneys from living donors were transplanted to patients from overseas who had come to the U.K. for treatment. Transplants between HL-A-identical siblings (i.e., siblings well matched for HL-A transplantation antigens) did extremely well, the success rate being nearly as great as between identical twins. But few living donors were used in the U.K., mainly because the possibility of donation within a family was seldom raised with relatives. Concern was expressed over the quality of cadaver kidneys being transplanted, the poor quality being caused in large measure by the shortage of available kidneys, and the legal uncertainties concerning their removal. According to the Bristol Registry records, ${ }^{1} 17 \cdot 3 \%$ of kidneys transplanted in the U.K. never functioned at all, and it was likely that in many of these the cause of primary failure was an unacceptably long period of warm ischaemia.

It was concluded that the shortage was very serious and that it could be completely overcome if even a small proportion of potential cases were used. Thus some 6000 fatal road accidents occurred a year. As each potential donor could usually provide two kidneys, these sources would be entirely adequate for all transplantation needs. Added to this would be suitable donor organs from patients with subarachnoid haemorrhage and cerebral tumours. The transplantation of irreversibly damaged kidneys, when it happened, was tragic, for it involved the patient in having two dangerous and useless operations-namely, insertion of the graft and then its removal, dashing the hopes 
of the patient, relatives, nurses, and doctors. The poor quality of kidneys transplanted in the U.K. was well known on the Continent, and though sharing of kidneys occurred between different countries many continental transplantation centres refused to accept kidneys from the U.K. because of the relatively high proportion of organs that were damaged by ischaemia.

\section{What are the Factors Responsible for the Shortage ?}

By far the most important factor was thought to be apathy in the medical profession. When keen young medical staff had transplantation in mind a small district general hospital could provide approximately six donors (i.e., twelve kidneys) a year. More common, however, was the apathetic lack of co-operation found in many hospitals and even in large teaching hospitals with active transplantation units. Some of the largest hospitals, including some with the highest prestige in the country, have provided no kidneys for transplantation.

The second factor was ignorance among the public and the medical profession of how serious the shortage is. Kidney transplantation had been carried out for so long now that many people felt that the state of affairs was satisfactory and that patients were receiving kidneys when they needed them.

Another important factor was fear among doctors that by being involved in organ donation they might in some way be contravening the law, with its present uncertainty of interpretation; or that they might meet with hostility from the relatives by asking permission for kidneys to be removed after death; or that they may be accused of hastening the death of a potential donor. There was also ignorance in the profession and among the public of the results of transplantation. It was important that the public should know that kidney transplantation provides a good chance of success and full rehabilitation in the community.

Despite the issuing of donor cards very few kidneys had been taken from donors carrying cards, and the carrying of cards became less popular after their legality was questioned by $\mathrm{Sir}$ Keith Joseph (then Minister of Health) in Parliament. It was felt that, though the public was mainly on the side of transplantation, enthusiasm was lacking because the degree of success was not well known.

It was pointed out that owing to the efforts of the Transplantation Registry ${ }^{9}$ renal transplantation had been documented more accurately than any other therapeutic procedure. The overall results were far better than the results obtained in the treatment of many common malignant diseases. Furthermore, the efforts devoted to patients requiring transplantation were important in relation to the average age of transplant patients; most were young wage earners, housewives, or children. Much medical and surgical effort in other spheres was concentrated on the elderly, who were often subjected to long and expensive treatments with poor results. This comparison was important because the question of the use of resources for transplantation was often raised.

Considering organ donation from the point of view of the neurosurgeon, Professor Jennett felt the public were ahead of the profession and often initiated the use of their relatives' kidneys for transplantation purposes when the doctors had not thought of it. Many of the doctors caring for potential donors felt insecure and did not wish to make any decision that might be questioned from the point of view of the law or on ethical grounds. Further, organ donation added to the work load of the ward. Many telephone calls had to be made to the transplantation unit, interviews were necessary with the relatives, and liaison with the transplantation team was essential. Many doctors felt they would rather not get involved in the time-consuming, troublesome, and perhaps worrying procedure of cadaveric organ removal.

Dr. Thurston pointed out that 3800 deaths were reported to him each year and that he had 45 hospitals under his jurisdiction. Only about half the reported deaths were from hospitals.
He was well known for his co-operative attitude towards transplantation, yet he received requests for use of organs for transplantation purposes less than six times a year. Most patients dying in hospital were not suitable as organ donors owing to the presence of disseminated cancer, sepsis, or atherosclerotic disease. However, a significant proportion of patients reported to the coroners were accident cases, and these formed a large proportion of kidney donors, the other main group of donors being cases of subarachnoid haemorrhage.

\section{The Law}

Mr. Skegg discussed the existing law $^{2-4}$ relating to cadaver "donors". The key provision is section 1 of the Human Tissue Act 1961. This section was drafted before clinical organ transplantation was established and the need for rapid removal of organs was fully appreciated. Section 1 (1) is a "contracting in" provision. It states:

"If any person either in writing at any time or orally in the presence of two or more witnesses during his last illness has expressed a request that his body or any specified part of his body be used after his death for therapeutic purposes or for purposes of medical education or research, the person lawfully in possession of his body after his death may, unless he has reason to believe that the request was subsequently withdrawn, authorize the removal from the body of any part or, as the case may be, the specified part, for use in accordance with the request."

S.1 (2) is in part a "contracting out" provision, but it also enables the spouse or relatives to veto the removal of organs, where the deceased did not request (in the manner specified in $S .1(1)$ ) that his organs be so used. It provides:

"Without prejudice to the foregoing subsection, the person lawfully in possession of the body of a deceased person may authorize the removal of any part from the body for use for the said purposes if, having made such reasonable inquiry as may be practicable, he has no reason to believe

(a) that the deceased had expressed an objection to his body being so dealt with after his death, and had not withdrawn it; or

(b) that the surviving spouse or any surviving relative of the deceased objects to the body being so dealt with."

S.1 (3)-(9) are relatively straightforward.

Discussion concerning the interpretation of the Human Tissue Act focused on two issues: (1) The identity of the "person lawfully in possession of the body," who must authorize the removal of any organs, whether under S.1 (1) or S.1 (2); (2) the question of what constitutes "such reasonable inquiry as may be practicable" for the purpose of S.1 (2).

It is necessary to distinguish between actual possession of the body and the right to possession of it. The hospital is in possession of bodies lying there. The executors, or whoever else is under the legal duty to dispose of the body, have the right to possession of it for that purpose-though this right is sometimes subject to the prior right of the coroner. If the hospital refuses to comply with the request of the person with a right to immediate possession of the body that the body be delivered up to him (or his representative), the hospital's possession becomes unlawful. But, until the body is claimed by the person with the right to possession of it, the hospital is "the person" lawfully in possession of any body lying there.

Where the hospital is in lawful possession, and the deceased was carrying an appropriately worded and signed "donor card," the case falls squarely within S.1 (1). Subject to the consent of the coroner in appropriate cases (S.1 (5)), the person designated by the hospital authority (under $S .1$ (7)) can, as a matter of law, authorize the removal of organs, even in the face of objections from the spouse or close relatives. No inquiry is necessary.

S.1 (2) deals with the situation where the deceased is not known to have requested (in the required manner) that his body be used for the purpose contemplated. There is no requirement that "all possible inquiries" be made concerning the matters 
specified in S.1 (2) (a) and (b). The duty to inquire is limited in two ways. First, the inquiry must be "reasonable." This statutory requirement implies that some inquiries are unreasonable. Mr. Skegg suggested it would be unreasonable to inquire of young children, or perhaps even of a very severely distressed spouse or parent whose health would be detrimentally affected in consequence, or who was seriously ill as a result of the accident in which the potential donor had died. However, S.1 (2) does not even require the making of "all reasonable inquiries." It requires only "such reasonable inquiry as may be practicable." Mr. Skegg said the practicability of the inquiry must be determined with reference to the purpose, specified in the Act, for which it is desired to use the organ. The Long Title of the Act indicates that S.1 was enacted "to make provision with respect to the use of parts of bodies of deceased persons for therapeutic purposes and purposes of medical education and research." These purposes are referred to in S.1 itself, and it is with regard to these purposes that the practicability of the inquiry must be determined. Regard must be had to the time within which the organ must be removed, if it is to be of use for the intended purpose. When it is desired to remove a kidney for transplantation, it is not practicable to make as extensive inquiries as, for example, when it is desired to remove corneas for transplantation, since if left in the body for more than one hour after cessation of respiration or circulation a kidney becomes irreversibly damaged, while the cornea remains viable for at least 12 hours.

Mr. Skegg was of the opinion that if, in the time available, a genuine attempt was made to contact anyone who might be expected to throw light on any previously expressed wish of the deceased, and on whether any spouse or relative objected, authority could be given for the removal of the organs in question. He conceded that this view (which is also that of the editor of the Criminal Law Review ${ }^{5}$ ) might not find acceptance, and that $S .1(2)$ is susceptible to other interpretations. However, he considered there was very little danger of a doctor being successfully prosecuted if he acted on the suggested interpretation, especially if the organ was required to save ife.

It should be pointed out that almost all accident cases reported to the coroner are subjected to a full necropsy, which entails the removal of all organs, and neither the individual in his lifetime nor his relatives have any legal right to object.

\section{THE CORONER AND PROCURATOR FISCAL}

There was some discussion of the circumstances in which it was necessary for coroners to refuse consent when this was sought under S.1 (5) (or in Scotland for the procurator fiscal to object). Dr. Thurston said that there was seldom difficulty in telling whether a body was likely to be investigated from the point of view of murder or manslaughter. In such cases organs should not be removed, as the removal of clothing would interfere with the taking of photographs, which might constitute important evidence. Most cases, however, did not fall within this category, and Dr. Thurston considered that coroners could give permission for organs to be removed in the majority of accident cases, including those which might lead to a prosecution for causing death by dangerous driving.

\section{Death of the Brain}

The traditional diagnosis of death depends on the cessation of spontaneous ventilation (breathing) and heart beat. These are not absolute criteria, however, because patients undergoing open heart surgery routinely have the function of their lungs and heart taken over artificially during the operation, and the brain is kept alive by the artificial circulation of oxygenated blood through the cerebral blood vessels.
Though the concept of brain death ${ }^{6-9}$ is not easy to explain to the layman, the extreme example of the victim of the guillotine is perhaps helpful. Nobody would consider the body, after the head has been severed, to represent an individual living being; yet the body could be resuscitated and the organs kept alive for a considerable period. This illustrates that death of the brain represents death of the individual but not the death of other organs such as the kidney, liver, and heart.

When the brain is destroyed, as with a head injury or brain haemorrhage, respiration ceases, but if ventilation is taken over by a machine then the heart may continue to beat for many hours, sometimes a day or two. The other organs, including the kidney, are maintained in this way but the brain remains dead. This is the condition of "brain death," and it is generally believed that once brain death has been diagnosed the ventilator should be stopped, because persistence is of no benefit to the patient or his relatives.

Though some organs can be used when death has been diagnosed by traditional means-namely, the absence of spontaneous breathing and heart beat-the quality of the organ donated is very much better if taken while the heart is still beating. That in effect means from a patient with brain death whose respiration has been taken over by a ventilator but whose heart is continuing to beat. The diagnosis of brain death is already part of normal practice among neurosurgeons and their close colleagues in anaesthesia and neurology, but there is now a need for a wider appreciation of this condition, because braindamaged victims are commonly resuscitated in all large hospitals. If there is any question of uncertainty the patient is always presumed to have a potentially recoverable state until proved otherwise. Once brain death is established, however, the question arises whether donor organs should be excised while mechanical ventilation is continued and the heart is still beating, provided permission has been obtained to remove organs after death. To remove the organ with the circulation intact has obvious advantages to the recipients, as there will be no anoxic damage. This procedure is already accepted practice in the United States, France, West Germany, Belgium, Denmark, and Switzerland. The surgeon most experienced in heart transplantation (Dr. N. Shumway, of California) considers it unethical to use a heart for transplantation unless it has come from a donor whose heart was still beating, for to transplant a heart that has stopped as a result of anoxia will give the recipient a severe initial handicap which he may not overcome.

When a ventilator is stopped the heart may continue beating for more than an hour, but the organs may suffer greatly from anoxia and acidosis. Many surgeons with experience of this type of organ donation feel that the procedure of waiting for the heart to stop is unsatisfactory from every point of view.

Though there has been considerable emphasis on brain death in this discussion it is important to realize that many kidneys come from patients in whom breathing and cardiac action have stopped, and where diagnosis of death is straightforward.

Professor Jennett emphasized that irrecoverable brain damage may occur in a patient who still has spontaneous respiration. Such tragic cases, in which activity of the brain stem is retained, are in an irreversible vegetative state and may survive for months, but they do not come under consideration as organ donors.

\section{Ethical Matters}

Bishop Huddleston felt that orthodox religious bodies tended to be conservative but the main religions approved of treatment of patients by transplantation and the donation from the dead of organs. He felt it was important that sufficient emphasis should be given to the dignity of the donor during death and after death. He thought that public opinion was ahead of the medical profession in terms of transplantation. It was important that what was advocated in transplantation was fully explained to the public. 
Dr. Gillie felt that the public should not be left out of decisions. In particular, relatives of dead patients, if available, would rather give part of their loved one's body than have it taken away. A request to use organs after death might not always increase distress of bereaved relatives. Sometimes this request was welcomed in that it provided the comfort that some good could come from the tragedy. What was needed was enthusiastic co-operation; the procedure of transplantation would then become a valuable experience for all concerned. If the public were involved apathy would disappear. The medical profession should adopt safeguards and the responsibility for each aspect of transplantation should be clearly defined.

Publicity could do a great deal of good, not only in providing co-operation from the public but also in persuading members of the medical profession, who had been apathetic in the past, to co-operate actively. There should be a code of ethics of medical practice in relation to transplantation.

\section{Recommendations}

\section{(i) DEATH}

The Committee agreed that there was a need to accept that a person was dead when it was established that he had suffered an irreversible cessation of brain function and was incapable of spontaneous respiration.

\section{(ii) CODE OF PRACTICE}

The Committee agreed that, to obtain public support and to increase the supply of donor organs, surgeons involved in organ transplantation should follow a code of practice containing desirable safeguards. The code the Committee proposes is set out below.

\section{(iii) CORONERS}

The Committee agreed that a letter should be sent to the secretary of the Coroners' Society requesting the co-operation of coroners in the supply of donors for transplantation. It would be helpful if there were greater uniformity of practice among coroners, so that transplantation surgery was not obstructed more than was necessary for the performance of the coroners' duties.

\section{(iv) PUBLIC EDUCATION}

The Committee agreed that it was desirable that there should be an intensive advertising campaign similar to that being held in Holland, in which the national press published advertisements and television and radio were used to explain transplantation. It is important that the results of organ transplantation are accurately represented. The public should know that most patients receiving kidney transplants are in their teens, $20 \mathrm{~s}$, or $30 \mathrm{~s}$, whereas the age for general medical and surgical patients is often around 70. If a patient receives a kidney from an identically matched sibling, the chances of long-term success are excellent. Even when cadaver donors are used, $50 \%$ of the initial transplants will still be functioning after two years and $70 \%$ of the patients will be alive. ${ }^{10}$ Some patients will have received second transplants or will have been returned to dialysis. The patient surviving longest with a cadaver transplant is now of more than 11 years' standing, and $90 \%$ of patients with functioning kidneys have been restored to the communitymen and women to work, housewives to running their homes, and children to school. These patients live life to the full and contribute greatly to the community; they often feel that the extra years resulting from transplantation must not be wasted. ${ }^{11}$

\section{(v) MEDICAL EDUCATION}

The Committee agreed that organ transplantation should form part of the undergraduate teaching curriculum, so that doctors can be fully appraised of the situation.

\section{(vi) CLARIFICATION OF THE LAW}

The Committee agreed that, in view of the unhelpful interpretation of the Human Tissue Act which persist in some quarters, statutory clarification of the Act was desirable.

The existing S.1 (2) (see above) should be repealed, and the following provision substituted:

"Without prejudice to the foregoing subsection, the person lawfully in possession of the body of a deceased person may authorize the removal of any part from the body for use for the said purposes if, having made such inquiry as is both reasonable and practicable in the time available, he has no reason to believe that the deceased had expressed an objection (which he was not known to have withdrawn) to his body being so dealt with after his death

"Provided that authorization shall not be given under this subsection if the person lawfully in possession of the body has reason to believe that the surviving spouse or any surviving relative of the deceased objects to the body being so dealt with".

In addition there should be a new subsection, providing that

"For the avoidance of doubt in the interpretation of this section, it is hereby declared:

"(a) That the hospital authority is the person in possession of the body of a deceased person lying in the hospital, and that this possession is lawful until such time as the hospital authority fails to comply with a request for possession of the body, made by the person who has the right to immediate possession of it.

"(b) That a printed but personally signed 'donor card', or other document, is 'in writing' for the purpose of subsection 1 of this section.

"(c) The 'time available', for the purpose of an inquiry under subsection 2 of this section, extends only until the moment at which steps must be taken to remove the part of the body, if it is to be suitable for the therapeutic or other purpose in question."

The effect of these provisions would be to overcome the unfortunate (and, it is thought, unjustified) doubts concerning the interpretation of "such reasonable inquiry as may be practicable" and "person lawfully in possession of the body" under the present law, and to prevent any doubts arising over the interpretation of "in writing."

Only in one respect does the suggested amendment seek to alter what the Committee understands to be the current legal position. Though authorization could not be given under the proposed S.1 (2) if the person lawfully in possession of the body had reason to believe that the spouse or any relative of the deceased objected, he would no longer be under a duty to make inquiries as to whether they did object. He would, however, invariably approach the closest available relatives, in the course of making "such inquiry as is both reasonable and practicable" to determine whether the deceased had expressed an objection. They would thus have the opportunity of making known their own (or others') objections. This change would represent a reversion to the legal position of the spouse and relatives under the Corneal Grafting Act, 1952, which was very much more satisfactory in this respect.

Some members of the Committee favoured a more radical amendment of the Human Tissue Act. But in view of the failure of more radical proposals to make progress through Parliament, and in view of the general concensus among surgeons that it would be undesirable to remove organs for transplantation in the face of objections from the spouse or relatives, it was decided to press for a limited amendment.

\section{(vii) REGISTER}

The Committee agreed it was desirable that a register be established listing name, date of birth, and address of persons who wish their bodies to be used for transplantation after their 
death, and of those who object to such use of their bodies. ${ }^{4}$ Provided ready access to this information was assured, such a register would greatly facilitate the inquiry reyuired by $S .1$ (2). It would also safeguard the interests of those persons who do not wish their bodies to be used for transplantation after their death.

\section{Proposed Code of Practice for Organ Transplantation Surgery}

(A) Before organs are removed from a body for transplantation purposes, death should be certified by two doctors, one of whom has been qualified for at least five years. Neither of these doctors should be members of a transplantation team.

(B) In cases of irreversible and total brain death, where respiration is dependent on mechanical ventilation, the decision to stop ventilation must have no connexion with transplantation considerations. Brain death would be established using agreed criteria. ${ }^{5}$ These have been evolved in several large centres, particularly in America, and have been in use for the last two to three years in some British centres. They were evolved for the purpose of rationalizing practice in a difficult area of decision-making, with a view to increasing the humanity of the service provided quite apart from the need for donor organs.

Thus:

"In patients with structural disease of the brain, in whom there is no suspicion of depressant drugs or hypothermia, brain death may be diagnosed if, over a period of 12 hours, both the following conditions are fulfilled:

"(i) No spontaneous respiration during 3 minutes of observation, the $\mathrm{PaCO}_{2}$ being $36-44 \mathrm{mmHg}$ prior to disconnecting the respirator; oxygen should be fed down the trachea during this test period.

"(ii) The brain stem reflexes absent: (a) pupils fixed, without evidence of second or third nerve lesion; $(b)$ oculo-vestibular reflexes absent; (c) no corneal reflex; $(d)$ no motor responses above foramen magnum level.

"Note that an E.E.G. need not necessarily be carried out, that reflex movements of the limbs may persist, and that blood pressure and heart rate are not taken into account. It is of course medical staff and not nurses who must elicit these signs and record them."

The criteria listed above are not concerned with the question of donor organs for transplantation, and no part of this code of practice has been proposed with a view to facilitating transplantation.

(C) Where it has been decided that death of the brain has occurred and mechanical ventilation is to be stopped, the question of organ removal will be discussed fully and sympathetically with available relatives so that their informed consent is obtained for the removal of organs either before or after mechanical ventilation is finally stopped.

(D) It is the responsibility of the surgeon removing the organs for transplantation purposes to satisfy himself that death had occurred and that the correct procedure had been followed in determining whether the deceased in his lifetime had objected. If no information concerning the deceased's wishes could be obtained, having made such inquiry as was both reasonable and practicable in the time available, there would be no reason to believe that the deceased had objected.

(E) If available relatives objected to the use of the deceased's organs for grafting, even if it were established that the deceased himself has not objected, the relatives' wishes would be followed.

(F) If the case came under the jurisdiction of the coroner, or in Scotland the procurator fiscal, the surgeon removing the organs for transplantation would ensure that to the best of his ability the case was not one involving murder or manslaughter, and any observations made during the course of removal of the organs which could be of medicolegal importance would be put to the coroner.

\section{Conclusion}

This report is mainly concerned with kidney transplantation, but in the future other organs will be transplanted in the U.K. and therapeutic transplants of the liver have already been performed. Dr. N. Shumway and his colleagues in Stanford have transplanted more than 70 hearts with results comparable with those obtained with cadaveric kidney transplantation. While transplantation does not confer, and is not intended to confer, immortality, it is a very worthwhile form of treatment for patients belonging to the younger age groups. Action is now required to provide patients with a treatment that should be available, and it is hoped that the proposals embodied in this report will help to alleviate the very acute shortage of organ donors. Pre-eminent among these proposals are clarification of the law and the provision of a code of practice for all involved in transplantation surgery. Thus it is hoped to gain the confidence and full co-operation of the medical profession, of coroners, and of the public at large.

A draft of this report was presented by the Committee to a meeting of the British Transplantation Society held on 16 October 1974. After a full discussion and the acceptance of several amendments it was unanimously adopted. Further, it was decided to publish it as a document for discussion by the public and by members of the medical profession, together with an addendum (below) summarizing the most important points that arose during the discussion of the report by members of the society. The report will be considered again by the society in the light of any comments that may arise from public discussion, and a final decision on further action to achieve the acceptance and implementation of the proposals will then be taken.

\section{Addendum}

Sir Michael Woodruff favoured a more radical approach to changing the law. On the question of cerebral death, he saw no objection to the diagnosis of death based on irreversible cessation of cerebral function provided the great majority of ordinary people were aware, and accepted, that doctors were using the word "death" in this way.

Mr. J. R. Salaman and others raised the question of a computer to act as a register of those opting in or out to be organ donors after death. It was felt that to set up a computer would be very expensive, and that some other form of register might be possible. Professor J. van Rood too thought that a computer would be expensive and he recommended a programme of films, posters, and other forms of publicity on television, radio, and in the newspapers. He suggested that representatives from appropriate bodies in Scandinavia and the Benelux countries should be invited to discuss methods of popularizing organ donation.

The question of payment for the additional work involved in removing organs and the liaison with transplantation centres was raised, and it was pointed out that in the United States the Federal Government had given generous financial support to cadaveric renal transplantation, and that this had been one of the factors responsible for the great improvement in the supply of organs in that country.

The amended report was accepted unanimously by the members present, and it was decided to publish it as a discussion document analogous to a Government Green Paper.

Copies of this report are obtainable from Professor L. Brent, General Secretary, British Transplantation Society, Department of Immunology, St. Mary's Hospital Medical School, London, W2 1PG. Any correspondence connected with the report should be sent to the above address.

\section{References}

1 Nelson, S. D., and Tovey, G. H., British Medical fournal, 1974, 1, 622.

2 Skegg, P. D. G., Cambridge Law fournal, 1974, 33, 130

3 Skegg, P. D. G., Medicine, Science and the Law, 1974, 14, 53.

4 Advice from the Advisory Group on Transplantation Problems on the Question of Amending the Hum anTissue Act 1961 . London H.M.S.O., 1969. 5 Lanham, D., Medicine, Science and the Law, 1971, 11, 16.

- Lancet, 1974, 1, 341. 
7 Mohandas, A., and Chon, S. N., Fournal of Neurosurgery, 1971, 35, 211.

8 Report of the Ad Hoc Committee of the Harvard Medical School to Examine the Definition of Brain Death, fournal of the American Medical Examine the Definition of B
Association, 1968, 205, 337.
${ }^{9}$ Beecher, H. K., New England fournal of Medicine, 1969, 281, 1070.

10 Advisory Committee to the Renal Transplantation Registry, fournal of the American Medical Association, 1973, 226, 1197

11 Tomlinson, S. A., British Medical fournal, 1974, 4, 553.

\title{
Occasional Survey
}

\section{The Summerland Disaster}

\author{
R. J. HART, J. O. LEE, D. J. BOYLES, N. R. BATEY
}

British Medical.fournal, 1975, 1, 256-259

\section{Summary}

The reception, admission, and subsequent management of casualties from the Summerland fire are described. A senior member of the staff assessed priorities and directed casualties to different prearranged teams, and a nurse was allocated to each patient to aid continuity of treatment and documentation.

Though regular revision and discussion of major accident procedures with all members of the hospital staff and co-ordination with other rescue workers is helpful expensive rehearsals are of limited value in a civilian incident.

\section{Introduction}

Some confusion is apt to occur in a non-specialized hospital when even a few patients with moderately serious burns are admitted as an emergency. The special care they need can impose considerable strain on the staff and the available facilities.

Noble's Hospital in Douglas is a general hospital which serves the 56000 residents of the Isle of Man as well as the 500000 yearly visitors. Of the 200 beds seven are in an intensive care unit formed six years ago. There is no separate burns unit as the number of seriously burnt patients treated is normally small. During the period August 1972 to August 1973155 patients with recent burns or scalds were treated in the casualty department and 12 were admitted. None needed resuscitation with intravenous fluids, and only two needed skin grafts.

On the evening of 2 August 1973 about 3000 people, mostly holidaymakers, were enjoying the facilities of the Summerland leisure complex. A fire, started in an adjacent kiosk, spread within minutes to engulf the whole building. During the rush towards the exits many were injured by being crushed or trampled upon, and others tried to jump to safety. Some were burnt as they tried to leave the building, and others inhaled smoke when returning to find lost relatives. Within minutes of the alarm being given casualties started to arrive at the hospital,

\section{Noble's Isle of Man Hospital, Douglas, Isle of Man}

R. J. HART, M.B., F.R.C.S., Surgical Registrar (present address: Christian Hospital, Chandraghona, Bangladesh)

J. O. LEE, M.B., F.R.C.S., Consultant Surgeon

D. J. BOYLES, M.B., F.F.A. R.C.S., Consultant Anaesthetist

N. R. BATEY, M.B., F.R.C.s., Consultant Surgeon brought by taxis and private cars as well as by ambulance. In response to radio appeals blood donors also arrived and the roads to the hospital were severely congested.

\section{Reception of Casualties}

The initial problems were to mobilize the necessary staff and equipment and sort out the patients as they arrived at the casualty department. The telephone operator called both resident and non-resident staff in accordance with the emergency regulations, which fortunately had recently been revised. Indeed there was shortly more help than could be used as all the medical and nursing staff and many volunteers offered their services. Blood donors were assembled in a nearby hall and 44 pints of blood collected. Most of the patients and their relatives arrived within 20 minutes of the alarm being given and nearly all within an hour. The large number of people in the casualty department caused some confusion and made it difficult for the hospital staff to keep in contact and work effectively together.

\section{Fatal Injuries}

Forty-eight people were dead on arrival at the hospital. The main causes of death were suffocation, carbon monoxide poisoning, burns, and multiple injuries from falling. A high proportion of the tracheae and bronchi contained soot. The 48 bodies were taken to the hospital mortuary and then to a nearby church hall where more space was available. They were labeiied by letter, and necropsies were performed over the next three days. The process of identification continued over the following week, during which time the bodies were preserved without refrigeration in a polythene tube tied at both ends. The tube contained $200 \mathrm{ml}$ of $4 \%$ formaldehyde and a similar quantity of formaldehyde injected intraperitoneally. Only 12 of the bodies were visually identifiable.

Positive identification was obtained in all cases but presented considerable problems. Property, such as jewellery and necklaces, was sometimes helpful. The final identification was by a combination of sex, approximate age, teeth (dentures or dental charts), and operations such as hysterectomy or caesarean section.

\section{Non-fatal Injuries}

As they arrived at the hospital soon after the incident even the extensively burnt patients were not severely shocked. Intravenous infusions were set up in the casualty department and 